\title{
Qualidade visual percebida por idosos em cenas de salas de estar
}

\section{Perceived visual quality by the elderly in scenes of living rooms}

\author{
Marina Holanda Kunst, Universidade Federal de Pernambuco \\ marinakunst7@hotmail.com
}

\author{
Lourival Costa Filho, Universidade Federal de Pernambuco \\ lourival.costa@ufpe.br
}

\begin{abstract}
Resumo
O envelhecimento da população brasileira está em constante crescimento. Assim, é fundamental reconhecer que a qualidade visual percebida em ambientes residenciais é importante para que o idoso desfrute de segurança e bem-estar na moradia, reforçando o chamado aging in place. Este artigo objetiva prover informações empíricas sobre os efeitos da complexidade, da novidade e da abertura em cenas de salas de estar na qualidade visual percebida por idosos. A investigação empírica foi delineada segundo a Teoria das Facetas e utilizou um questionário online, elaborado por meio do Google Forms, baseado no Sistema de Classificações Múltiplas, como método para coletar os dados, analisados pela técnica multidimensional e não paramétrica Análise da Estrutura de Similaridade. Os resultados empíricos revelaram que a complexidade, a novidade e a abertura são categorias aderentes para a avaliação proposta, e que cenas de salas de estar tradicionais, com complexidade moderada e vistas desobstruídas influenciam, de modo consensual entre gêneros, na qualidade visual percebida pelos idosos consultados.
\end{abstract}

Palavras-chave: Idosos, Salas de estar, Qualidade visual percebida.

\begin{abstract}
The aging of the Brazilian population is constantly growing. Therefore, it is essential to recognize that the visual preference of residential environments is important for the elderly to enjoy security and well-being at home, reinforces the so-called aging in place. This article aims to provide empirical information on the effects of complexity, novelty and opening on perceived visual quality by the elderly in scenes of living rooms. The empirical investigation was designed according to Facets Theory and used an online questionnaire, elaborated through Google Forms, based on the Multiple Sorting Procedure, as a method to collect the data, analyzed through the multidimensional and non-parametric technique Similarity Structure Analysis (SSA). The empirical results corroborate that complexity, novelty and openness adhere to the focus of the assessment, that scenes from traditional, unobstructed and moderately complex living rooms influence, consensually for both genders, the perceived visual quality by the elderly consulted.
\end{abstract}

Keywords: Elderly, Living rooms, Perceived visual quality. 


\section{Introdução}

O envelhecimento da população brasileira está em constante crescimento. Um comparativo feito pelo Instituto Brasileiro de Geografia e Estatística mostrou que a população de 2019 aumentou, se comparado a 2012, pois o grupo de 60 a 64 anos registrou um crescimento de 4,9\%; enquanto que a parcela de pessoas com 65 anos de idade ou mais representava 10,8\% da população (IBGE, s./d.).

Esse crescimento, que reflete a diminuição do número de nascimentos e o aumento de idosos, segundo Oliveira e Rossi (2019); Porto e Rezende (2016), fará com que o número de idosos seja superior ao número de crianças. Os autores ainda destacam que, por volta de 2050, o Brasil estará entre os cinco países com as maiores populações idosas do mundo.

Já Morais (2016) afirma que as projeções das Nações Unidas - para o ano de 2050 - mostram que o índice de envelhecimento brasileiro será menor que o da Europa Ocidental e do Leste Asiático e o país deverá encontrar-se na $81^{\mathrm{a}}$ posição do ranque mundial.

Dessa forma, é importante entender que o processo de envelhecimento compreende mudanças sociais, físicas, psíquicas e biológicas das pessoas. Além disso, à medida que as pessoas envelhecem, os ambientes residenciais, principalmente, tornam-se mais importantes para os idosos, pois são essenciais para o atendimento de suas necessidades.

Assim, é fundamental reconhecer que a qualidade visual percebida em ambientes residenciais é importante para a compreensão das relações sociais que o idoso mantem na moradia, seja com familiares, vizinhos ou até mesmo a forte interação com os próprios ambientes, reforçando o chamado aging in place.

Logo, a adequação dos ambientes residenciais aos idosos, principalmente quanto ao reforço dos sentimentos de pertencimento e de identidade, é fundamental para que a pessoa idosa desfrute de segurança e bem-estar na moradia, já que esses ambientes influenciam a qualidade de vida do idoso e normalmente são vistos como lugares desafiadores e/ou hostis (KUNST et al., 2021; LEWIS e BUFFEL, 2020).

Ainda sobre esse assunto, Oswald e Wahl (2005) salientam que a moradia é onde o idoso está mais presente e, portanto, é o espaço onde mais manifesta o desejo de permanecer nele, pois acaba por se tornar um lugar de significados para este.

Rowles, Oswald e Hunter (2003) afirmam que os idosos estão presentes dentro da casa, mantendo sua independência. Isso demonstra a importância de os ambientes internos da moradia serem muito mais do que meramente os espaços físicos que habitam. Para a maioria das pessoas, principalmente os idosos, esses lugares nutrem uma sensação de "estar no lugar". E mais, os espaços interiores da casa podem se tornar um lugar de segurança e proteção para o idoso.

Esse fato fez com que a sala de estar fosse o ambiente residencial escolhido como objeto de estudo empírico desta pesquisa, estando associada com o receber e, por conseguinte, com as relações sociais que o idoso mantêm no interior de sua residência.

Para que essas relações sociais sejam favorecidas, Bonaiuto, Fornara e Bonnes (2003) asseveram que o idoso precisa se sentir satisfeito com sua residência, que é, então, uma 
experiência de prazer ou gratificação decorrente de morar em um determinado local, envolvendo três componentes principais do construto psicológico da atitude (cognição, afeto e comportamentos).

Estudos na área da Estética Ambiental apontam para categorias preditoras da preferência ambiental, sejam elas: ordem, complexidade moderada, naturalidade, conservação, abertura e novidade. Contudo, a complexidade, a novidade e a abertura foram tomadas para estudo nesta pesquisa, pela influência delas para a qualidade visual percebida em salas de estar.

A complexidade está relacionada com a quantidade e a variedade de elementos em uma cena. A novidade descreve lugares percebidos como tendo um estilo inovador ou tradicional. A abertura refere-se a espaços com vistas obstruídas ou desobstruídas para o exterior (NASAR, 2008).

De acordo com Nasar (2000), certas categorias ambientais têm importantes impactos na experiência humana, podendo evocar fortes emoções como prazer ou desprazer, atuar como efeito atraente ou calmante e possibilitar inferências sobre lugares e pessoas. Podem também influenciar o comportamento humano, de modo que as pessoas estão mais propensas a visitar locais que julguem favoráveis e a evitar outros percebidos como desfavoráveis.

Apesar de as respostas avaliativas, por si só, não poderem prever o comportamento real, a avaliação combinada desse tipo de respostas e do comportamento presumido dá uma boa indicação do comportamento real (NASAR, 2008). Por isso, nesta pesquisa, foi solicitado para os idosos participantes avaliarem em que medida diferentes cenas de salas de estar favoreciam na escolha de visitar ou permanecer.

Isso posto, o presente artigo apresenta como objetivo geral prover informações empíricas sobre os efeitos da complexidade, da novidade e da abertura em cenas de salas de estar, na qualidade visual percebida por idosos.

Ademais, a pesquisa foi delineada segundo a Teoria das Facetas; não houve controle na distribuição dos questionários online, por isso, não é possível definir a unidade geográfica, mas a amostra de idosos foi composta pelos sexos masculino e feminino, escolhidos aleatoriamente e sem intenção, cabendo destacar que as respostas avaliativas obtidas com esses dois diferentes gêneros foram consideradas em separado, visando detalhar melhor os resultados empíricos.

Foram ainda delimitados os seguintes objetivos específicos: 1 | constatar se as categorias de complexidade, novidade e abertura são aderentes ou não para a avaliação pretendida; 2| examinar os efeitos das categorias de complexidade, novidade e abertura na qualidade visual percebida em cenas de salas de estar por idosos; 3 | analisar se há consenso dos resultados entre idosos do sexo masculino e do feminino.

\section{Considerações teóricas}

A qualidade visual percebida é um constructo psicológico, pois envolve avaliações subjetivas. Apesar de a qualidade visual percebida depender, em parte, de fatores perceptuais/cognitivos, por definição, ela é um julgamento emocional que envolve avaliação e sentimentos (NASAR, 1988; COSTA FILHO, 2012). 
Dessa forma, pensar ou experienciar um ambiente envolve diferentes tipos de julgamentos. Um primeiro, surge da pessoa para o ambiente e da interação contínua entre os dois; enquanto um segundo refere-se aos sentimentos da pessoa para esse ambiente. Esses julgamentos dependem, portanto, tanto de fatores ambientais como humanos, que podem influenciar a resposta estética e o comportamento do observador/usuário.

Nesse contexto, na avaliação estética, é necessário observar o comportamento do sujeito, pois, no geral, percebe-se que as experiências estéticas são mediadas por fatores gerais e da pessoa em si (HEATH, 1988). Afinal, como os julgamentos sobre a preferência ambiental variam aleatoriamente de uma pessoa para a outra, são uma poderosa ferramenta para entender o que cada uma delas considera em relação à estética do ambiente (KAPLAN, 1988).

Cumpre destacar, entretanto, que um ambiente terá uma resposta estética favorável ou parecerá bom suficiente se um número significativo de pessoas comuns que o experienciam regularmente, ao invés de especialistas, assim o acharem (NASAR, 1988; COSTA FILHO, 2012).

Pesquisadores e projetistas ambientais buscam princípios universais que possam explicar semelhanças e diferenças nas respostas estéticas. As pesquisas apontam para seis características visuais relacionadas com as respostas humanas para o ambiente: ordem, complexidade moderada, naturalidade, manutenção, abertura visual e novidade (NASAR, 2000). Ambientes com essas características tendem a ser avaliados positivamente.

Nesta pesquisa, como dito antes, foram tomadas três dessas características visuais preditoras da preferência ambiental para estudo - complexidade, novidade, abertura - no sentido de testar seus efeitos na qualidade visual percebida por idosos em cenas de salas de estar.

A complexidade envolve o número de elementos e distinção entre eles, em uma cena. Quanto mais elementos diversificados, mais complexo o ambiente será. A complexidade aumenta a incerteza, o estímulo e o tempo em que as pessoas passam observando o espaço (NASAR, 2008). A partir das sugestões teóricas, espera-se que, presumivelmente, o idoso aponte a qualidade visual percebida em cenas de salas de estar, relacionadas com complexidade moderada, visto que deseja ambientes com moderado número e variedade de elementos.

A novidade, apresentada por Berlyne (1972) como uma variável colativa e definida como o grau de discrepância entre os estímulos experienciados, varia de objeto para objeto e do momento em que o objeto é avaliado (HEATH, 1988). A teoria sugere que o idoso avalie o ambiente de sala de estar quanto à novidade no nível tradicional, por ser um reflexo de suas experiências com esse espaço durante os anos.

A abertura tem a ver com a permeabilidade e a altura das barreiras, e está relacionada com o sentido de ambiente enclausurado ou visualmente aberto. Subir a altura, ou diminuir a permeabilidade dos elementos que limitam um espaço, aumenta o enclausuramento percebido. A variação no fechamento tem uma grande influência na percepção, porque muda tanto o que os humanos podem ver e prever no ambiente, além de facilitar com que eles possam se mover através dele (NASAR, 2008). A teoria sugere que os idosos prefiram ambientes desobstruídos, ou seja, com abertura, confirmando o que Nasar (1988) expressa dessa categoria está relacionada com uma vista aberta, e que uma vista restrita pode limitar as habilidades e os movimentos livres. 
Diante do exposto, pelas sugestões teóricas levantadas e aqui apresentadas, tem-se como pressuposto teórico que cenas de salas de estar tradicionais - partindo da premissa de que idosos preferem o estilo familiar ao inovador - com complexidade moderada e vistas desobstruídas sejam relacionadas à qualidade visual percebida pelas pessoas idosas consultada.

\section{Considerações Teórico-Metodológicas}

A Teoria das Facetas (TF) foi escolhida para delinear esta pesquisa. A TF, proposta e desenvolvida por Louis Guttman, é entendida como uma meta-teoria utilizada para definir e planejar o conteúdo de uma investigação. A definição é fornecida pelo fato de especificar as "facetas" inerentes às variáveis estudadas e às relações conceituais entre elas (ROAZZI e DIAS, 2001; BILSKY, 2003).

Costa Filho (2014) afirma que a TF trata de verificar se a estrutura teórica - construída pelo pesquisador - é encontrada na estrutura dos dados empíricos que são graficamente apresentados, visando controlar a correspondência entre os níveis teórico e empírico de uma pesquisa. Assim, a TF permite integrar conceitos e dados para facilitar sua legitimação em sistemas multidimensionais, bem como, permitir medições com base nas teorias. Para tal, propõe, no trabalho citado, procedimentos para a identificação dos componentes conceituais da pesquisa e a descrição de suas relações.

A TF, a partir do delineamento de facetas, define uma pesquisa específica que pode ser resumida em uma sentença estruturada (mapping sentence), aqui proposta como um modelo conceitual para a avaliação da qualidade visual percebida em cenas de salas de estar por idosos.

A sentença estruturadora, além de citar as diferentes facetas de interesse científico, também especifica as suas relações mútuas, usando nexos como na língua falada. A sentença é lida "da esquerda para a direita", resultando em tantas frases quantas diferentes combinações existam entre os elementos pertencentes ao campo do interesse (BILSKY, 2003).

Segundo Bilsky (2003), diferenciam-se três tipos de facetas. O primeiro se refere à população dos sujeitos. O segundo ao conteúdo das variáveis pesquisadas. Essas duas facetas, juntas, determinam o domínio de interesse da pesquisa. O terceiro se refere ao universo ou amplitude das respostas admissíveis, normalmente apresentadas como uma escala ordenada de aceitação.

A população que avaliada nesta pesquisa foi constituída por pessoas idosas. Os diferentes grupos, separados por gênero, são: 1| idosos do sexo masculino; 2| idosos do sexo feminino.

O próximo passo foi determinar as facetas de conteúdo e seus elementos internos, os referentes da experiência ambiental, relacionados com a complexidade, a novidade e a abertura, presentes em cenas de salas de estar.

A primeira faceta de conteúdo, "complexidade", refere-se à característica de envolvimento. Reflete o quanto há para se olhar. Se há pouca coisa, é provável que a preferência seja baixa. $\mathrm{O}$ nível médio de complexidade é reconhecido como o mais agradável em relação àqueles com complexidade mínima e máxima. Nessa perspectiva, essa faceta teve seus elementos internos estabelecidos considerando esses três níveis: (X1) mínimo; (X2) moderado; (X3) máximo. 
A segunda faceta de conteúdo, "novidade", refere-se ao grau de discrepância entre o estímulo experienciado no momento e anteriormente. Em termos gerais, a preferência por novidade envolve um ambiente: (Y1) tradicional; (Y2) inovador.

A terceira faceta de conteúdo, "abertura”, está relacionada com a permeabilidade visual. Uma visão mais ampla favorece a pessoa a observar e entender a cena; enquanto que o oposto pode limitar essa capacidade. Sob esse prisma, foram consideradas duas possibilidades de ambiente como elementos internos: (Z1) obstruído; (Z2) desobstruído.

O próximo passo é informar a amplitude de respostas possíveis de se obter dos participantes. Esse racional é comum a todas as facetas e, por conseguinte, à pergunta formulada através da sentença estruturadora para a avaliação da qualidade visual percebida em cenas de salas de estar por idosos. Foi considerada uma escala do tipo "Likert", com cinco intervalos: 1| nada; 2| pouco; $3 \mid$ mais ou menos; $4 \mid$ muito; $5 \mid$ demais, valorados segundo os números que os antecedem na tabulação dos dados brutos obtidos.

Os elementos das facetas de conteúdo podem ser organizados de forma semelhante a uma análise combinatória (X3 x Y2 x Z2), produzindo, ao todo, um conjunto com 12 cenas de salas de estar, obtidas através do site Google Imagem, que transmitem uma relação ou situação específica a ser investigada.

Como uma referência inicial da pesquisa, a sentença estruturadora para a avaliação da qualidade visual percebida em cenas de salas de estar por idosos (Figura 1) será analisada em relação aos resultados empíricos que devem contestar ou corroborar essa estrutura.

Em que medida a pessoa idosa x (do sexo masculino | do sexo feminino) avalia que as características de

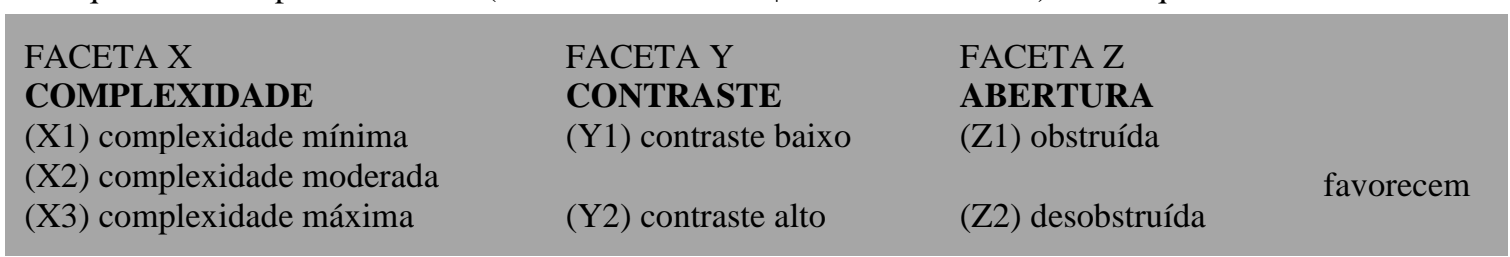

\section{RACIONAL}

(1) nada

(2) pouco

(3) mais ou menos estar e/ou permanecer em salas de estar

(4) muito

(5) demais

[expressão da qualidade visual percebida]

Figura 1: Sentença estruturadora para a avaliação da qualidade visual percebida por idosos em cenas de salas de estar

\section{Considerações Metodológicas}

A investigação utilizou um questionário online (Figura 2 - próxima página), elaborado por meio do Google Forms, baseado no Sistema de Classificações Múltiplas - adaptado por Canter, Brown, Groat (1985) -, como método para coletar os dados. 


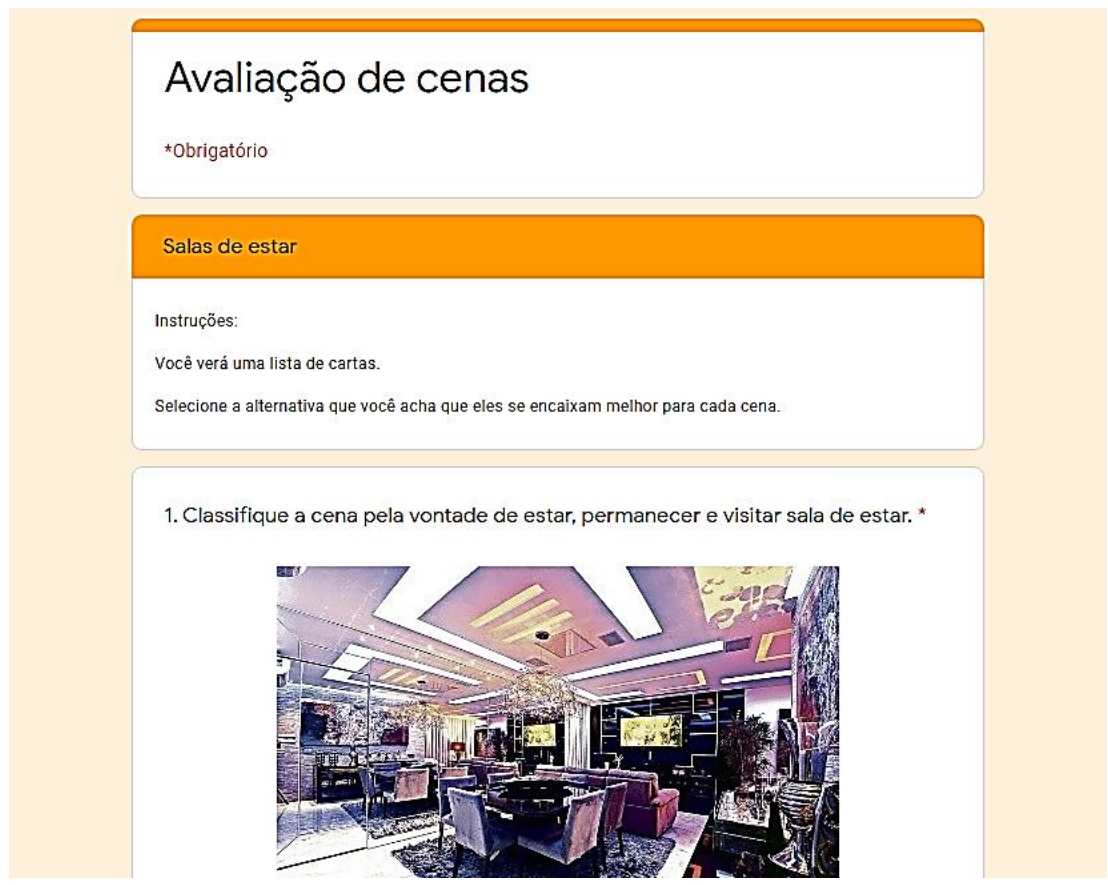

Figura 2: Recorte de tela do questionário online proposto

Para o planejamento da etapa empírica, os idosos eram convidados a participar da pesquisa por meios de comunicação via mensagens por aplicativos de rede de contatos dos pesquisadores e, também, foi solicitado que as pessoas inicialmente contatadas, caso pudessem, divulgassem a pesquisa entre seus conhecidos idosos.

O Sistema de Classificações Múltiplas solicita ao entrevistado que façam categorizações discretas de um conjunto de elementos [fotografias, como desenvolvido por Groat (1982)] com base em julgamentos de semelhanças relativas entre esses elementos, clasificando-os várias vezes a partir de critérios definidos pelo pesquisador, sendo esta definida como classificação fechada (CANTER, BROWN, GROAT, 1985; SILVA e COSTA FILHO, 2020).

O questionário consistiu em um cabeçalho inicial para o preenchimento de dados pessoais dos participantes e assinatura virtual do Termo de Consentimento Livre Esclarecido (TCLE), seguido da classificação das fotografias selecionadas pelo Google Imagens (Figura 3).

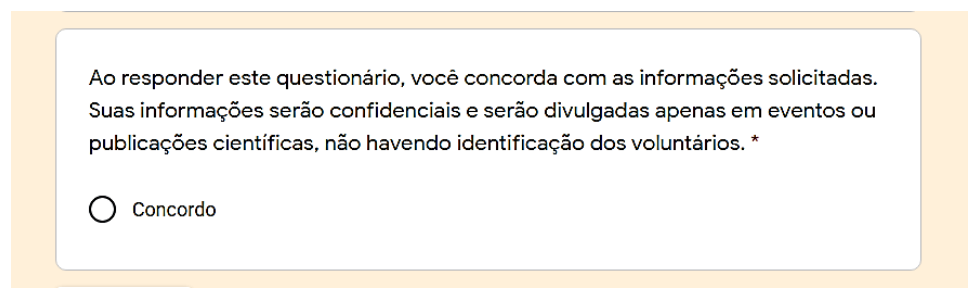

Figura 3: Imagem do questionário online proposto

A manipulação sistemática dos diferentes níveis das três categorias estéticas tomadas para estudo, representadas nas cenas de salas de estar, foram validadas por um corpo de juízes composto de 9 alunos do Programa de Pós-Graduação em Design da Universidade Federal de Pernambuco - PPGDESIGN/UFPE, antes de serem disponibilizadas como elementos de estímulo apresentados no questionário online. 
Após as deliberações dos juízes, ficou definido o conjunto de 12 cenas de salas de estar, representando precisamente a relação entre todas as facetas de conteúdo, listadas na sentença estruturadora, todas coloridas e de mesmo tamanho (Figura 4). Ademais, tomou-se o cuidado de utilizar cenas sem a presença de pessoas, no sentido de não atuarem como covariáveis da preferência ou da não-preferência ambiental.

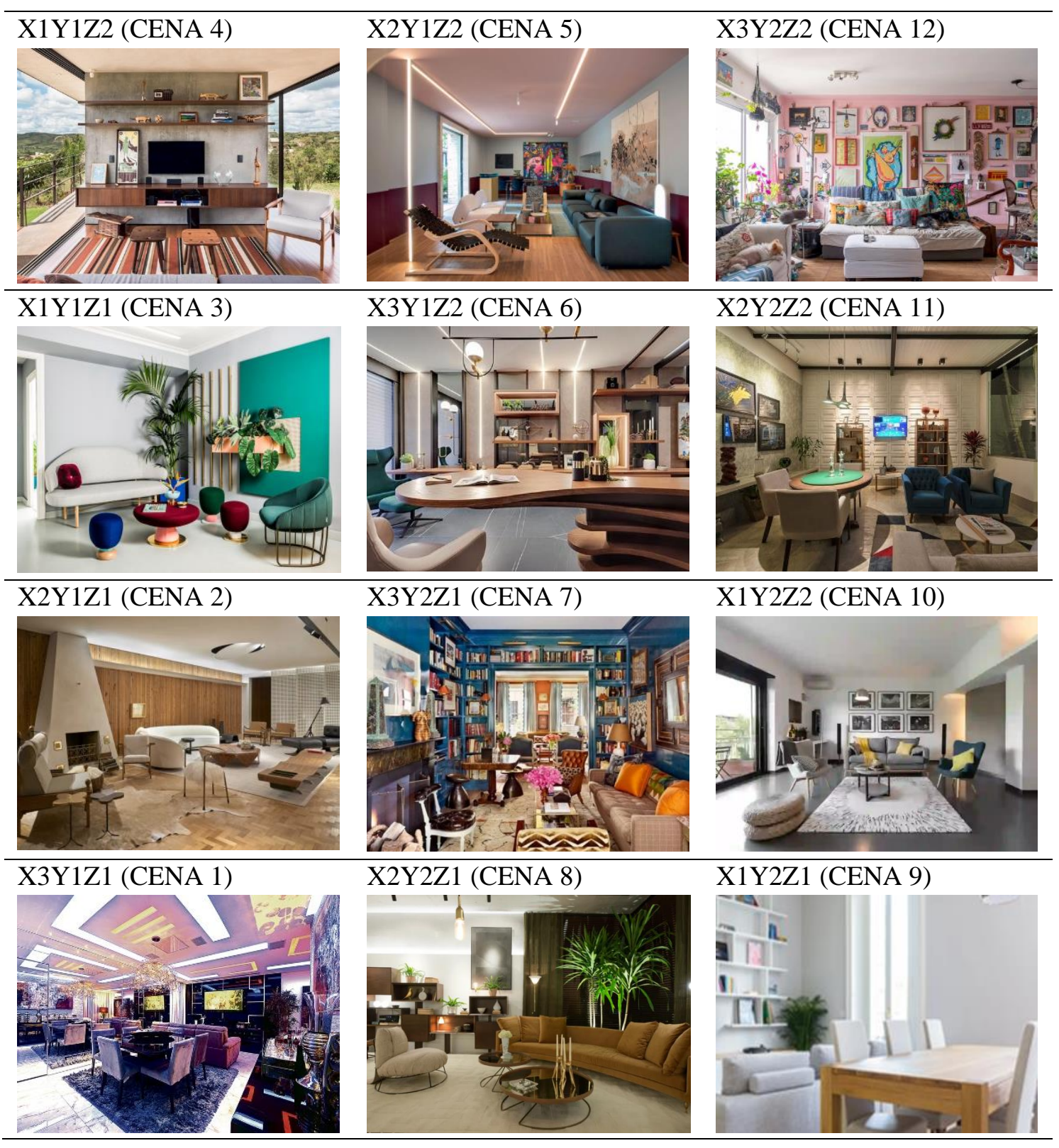

\begin{tabular}{l|l|l}
\hline \multicolumn{3}{c}{ Legenda } \\
\hline Complexidade (X) & Novidade (Y) & \multicolumn{1}{c}{ Abertura (Z) } \\
\hline Mínima (X1) & Inovador (Y1) & Obstruída (Z1) \\
Moderada (X2) & & \\
Máxima (X3) & Típico (Y2) & Desobstruída (Z2) \\
\hline
\end{tabular}

Figura 4: Cenas de salas de estar correlacionando as categorias de complexidade, novidade e abertura

Após a descrição do objetivo da pesquisa e da assinatura do TCLE, os idosos participantes eram instruídos sobre a pesquisa com o seguinte texto: "classifique em que medida cada uma das cenas de salas de estar favorece estar, visitar e permanecer". 
Encerrada a coleta de dados, as respostas computadas foram transferidas para uma planilha digital que, posteriormente, alimentou o programa informático HUDAP, utilizado para auxiliar a Análise da Estrutura de Similaridade (Similarity Structure Analysis - SSA). Os dados sociodemográficos dos participantes foram também tabulados para possibilitar a descrição e a caracterização da população amostral.

A escolha da SSA deu-se devido a ela ser uma técnica geométrica para auxiliar a compreensão da estrutura espacial de matrizes de correlação ou matrizes de coeficientes de similaridade entre variáveis. Essa técnica tenta chegar a unidades de escala para um sistema de dimensões de estímulos substantivamente significativas. Portanto, compreende uma classe de modelos que representa semelhanças entre objetos ou ambientes em um espaço multidimensional, para permitir que se apreenda mais facilmente as inter-relações e padrões presentes nos dados (AMAR e LEVY, 2014; BORG e LINGOES, 1987; BILSKY, 2003).

Segundo Costa Filho (2014), a Teoria das Facetas parte da suposição de que as facetas assumem um papel específico na estruturação do espaço multidimensional do mapa da SSA. Uma faceta ordenada apresenta elementos contidos em ordem hierárquica e pode ter faixas paralelas (axial) ou configurações circulares (modular). Além das facetas ordenadas, existem outras cujos elementos se diferenciam de modo qualitativo, mas sem qualquer ordem óbvia (polar). Nesse caso, os elementos geralmente constituem regiões cuneiformes, com limites partindo de uma origem comum (Figura 5 a, b e c).

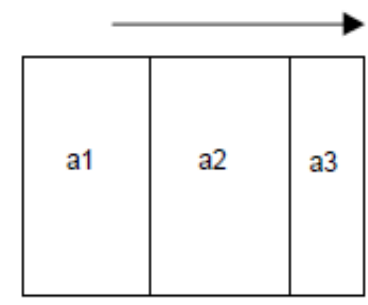

a | Axial

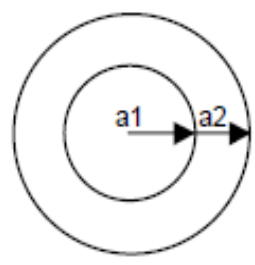

b | Modular

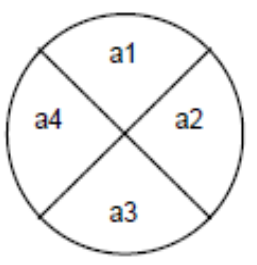

c| Polar

Figura 5: Papéis das facetas e suas partições no espaço multidimensional

As análises das projeções geométricas a serem produzidas pela SSA para esta investigação, uma para cada característica dos elementos ambientais de salas de estar, podem revelar relações e regras implícitas aos dados obtidos, que seriam imperceptíveis nas análises quantitativas usuais.

\section{Considerações empíricas}

No final, a coleta de dados envolveu a participação de 71 idosos, todos residentes no Brasil. Os dados coletados referiam-se, além das avaliações das 12 cenas de salas de estar, à idade e ao sexo dos respondentes. Dessa forma, observou-se que, em sua maioria, as mulheres foram mais presentes $(78,9 \%)$ e a idade variou entre 60 a 83 anos.

Os dados obtidos foram tabulados em uma planilha do Microsoft Office Excel, visando ordenar as respostas e seus respectivos escores. Esses dados brutos alimentaram o HUDAP, caracterizando-se como informações necessárias para iniciar o processamento do SSA. 
Os dados plotados foram computados e produziram uma matriz de correlação entre as variáveis, representadas por pontos no espaço do SSA (Figura 6). Esses dados geram um diagrama de espaço ou espaço euclidiano, em que cada faceta de conteúdo foi testada para responder aos objetivos formulados.

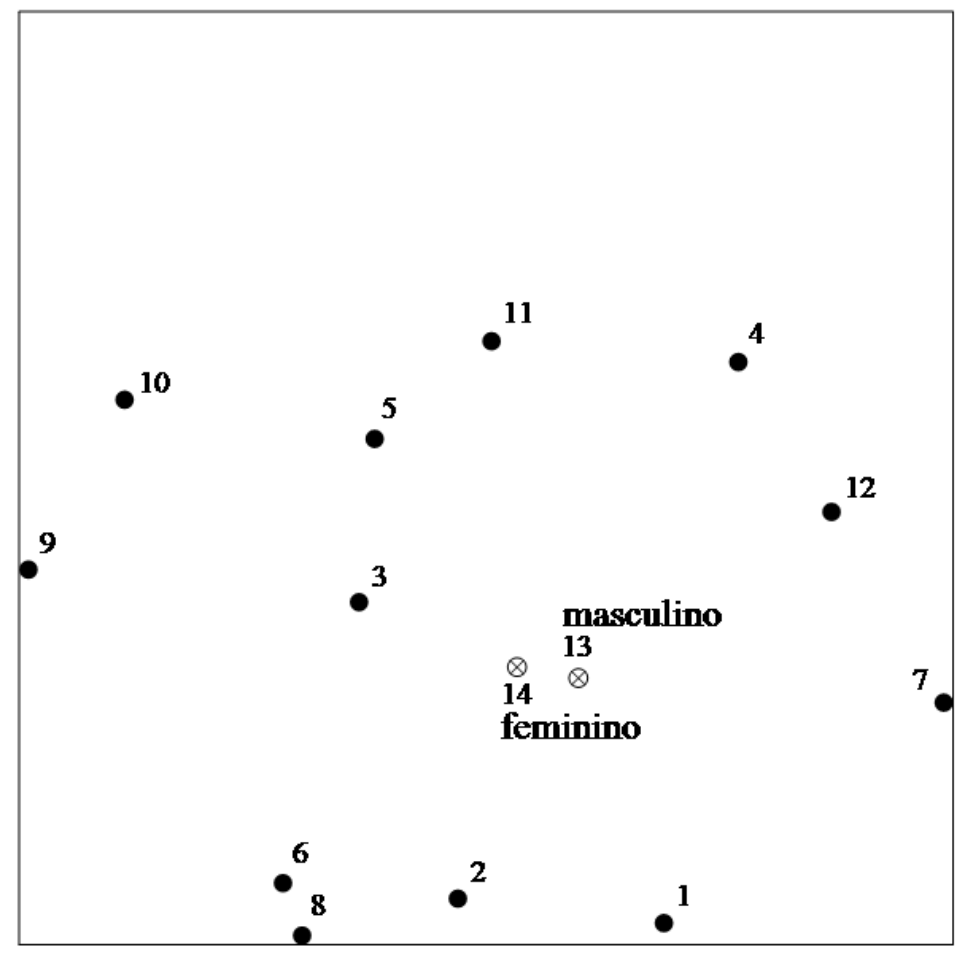

Figura 6: Diagrama Original do espaço da SSA

A matriz de correlação foi de 12 por 12 e sua análise mostrou que a maioria dos coeficientes foram positivos e variaram de $-.13 \mathrm{a}+.81$. Esses coeficientes mostraram as semelhanças e dessemelhanças percebidas entre as 12 diferentes cenas de salas de estar, na qualidade visual percebida por idosos.

Dadas essas características da representação das correlações entre as variáveis da pesquisa, foi possível testar cada faceta adotada - complexidade, novidade, abertura - sobre o diagrama dos pontos originais da SSA para a qualidade visual percebida em cenas de salas de estar.

A cena 8 (X2Y2Z1) é alta e positivamente correlacionada (+.81) com a cena 6 (X3Y1Z2 e, por essa razão, aparecem espacialmente muito próximas no diagrama da SSA. Já a cena 9 (X1Y2Z1) está negativamente correlacionada (-.16) à cena 7 (X3Y2Z1), que, consequentemente, estão distantes espacialmente, ou seja, modularmente opostas nos mapas SSA (Figura 6).

Para testar cada faceta no diagrama original da SSA, foram atribuídas cores para as 12 cenas, a depender de cada elemento interno da faceta. Em seguida, verificou-se a existência de padrões de contiguidade regional, ou seja, padrões reconhecíveis de divisão do espaço em regiões formadas pelas cenas de um mesmo elemento da faceta considerada, em todas as facetas testadas.

Os resultados dos diagramas da SSA mostram que as três facetas testadas - complexidade, novidade, abertura - formaram estruturas regionais de contiguidade entre os itens de um mesmo elemento interno, confirmando a aderência das facetas para a avaliação da qualidade visual percebida por idosos em cenas de salas de estar. 
Explorando o mapa da SSA da Faceta X, complexidade, é possível perceber que os idosos participantes captaram essa categoria, a qual formou regiões de contiguidade coerentes com a ordem hierárquica dos seus elementos internos.

A Figura 7 descreve duas formas circulares que dividem o espaço em três regiões distintas. Trata-se de uma faceta que tem um papel claramente modular, em que esse conjunto de linhas tem uma origem central localizada na forma circular central do mapa (complexidade moderada), onde os pontos em azul estão presentes.

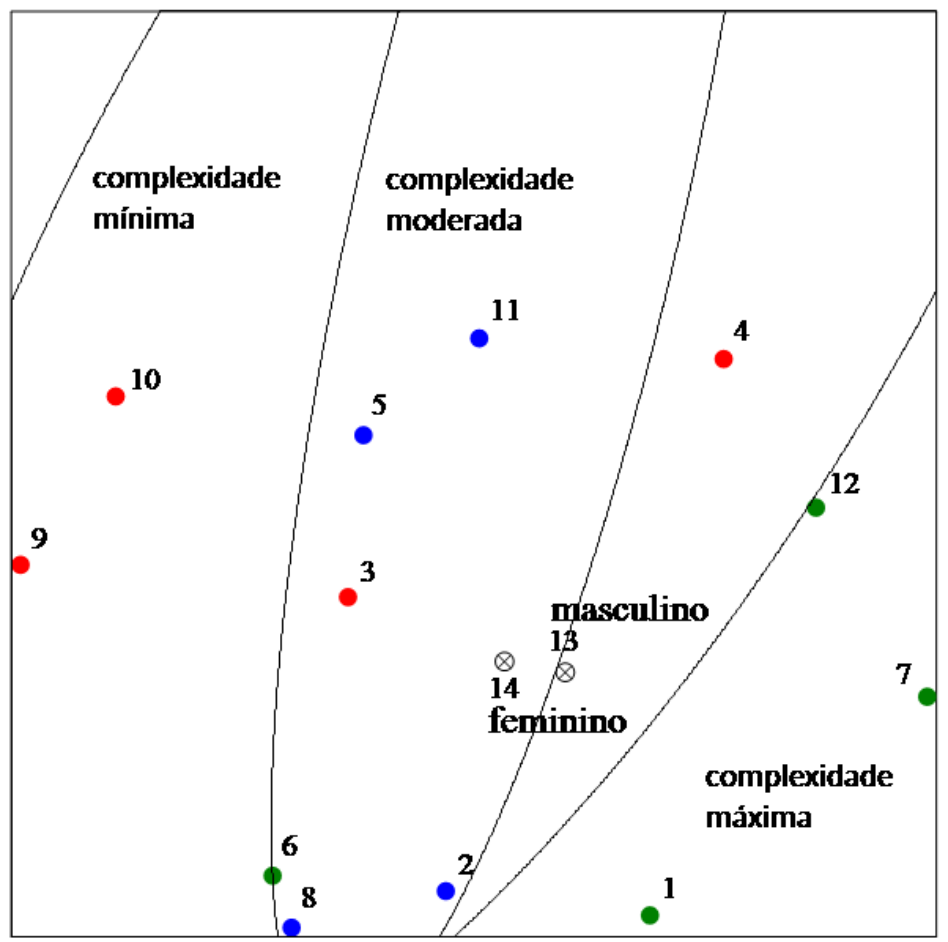

Figura 7: Diagrama do espaço da SSA com o teste para a FACETA X (COMPLEXIDADE)

Além disso, os itens representados na parte central do mapa têm um caráter mais geral e regulador para a avaliação sugerida em relação às regiões periféricas, que representam aspectos mais específicos da situação pesquisada. Essa região central concentra as cenas 2, 5, 8, 11 (complexidade moderada), 3 (complexidade mínima) e 6 (complexidade máxima), ou seja, os idosos participantes são mais influenciados pela complexidade moderada, quando avaliam a qualidade visual percebida em cenas de salas de estar.

Na Figura 7, notam-se três exceções. A primeira, cena 4, considerada com complexidade mínima, mas percebida como moderada. A segunda, cena 3, julgada com complexidade mínima, mas captada como moderada. A terceira, cena 6, pensada com complexidade máxima, mas avaliada como moderada. Essas exceções, entretanto, não invalidam os resultados obtidos.

Ainda considerando a Figura 7, observa-se que o grupo feminino está localizado na região que reúne as cenas de salas de estar com complexidade moderada; já o grupo masculino, localizado na fronteira entre duas regiões, por essa razão, também pode ser tomado como sendo influenciado pela complexidade moderada na avaliação da qualidade visual percebida em cenas de salas de estar, assim como o grupo feminino. Dessa forma, há consenso desses resultados entre os grupos de participantes idosos do sexo masculino e do feminino. 
Ao analisar o mapa da SSA para a Faceta Y, novidade, também se percebeu que os participantes captaram essa categoria e que foram formadas regiões de contiguidade coerentes com a ordem hierárquica considerada para sua formação.

A Figura 8 apresenta um círculo que divide o espaço euclidiano em duas regiões. Essa faceta, como as anteriores, tem um papel modular. Na região central do mapa, estão reunidas as cenas de salas de estar com caráter inovador, representadas pelos pontos em vermelho, aspecto que, pela posição que ocupa no mapa da SSA, revela-se como central para a avaliação proposta; enquanto que o caráter tradicional, na periferia do mapa, estaria relacionado às questões mais específicas.

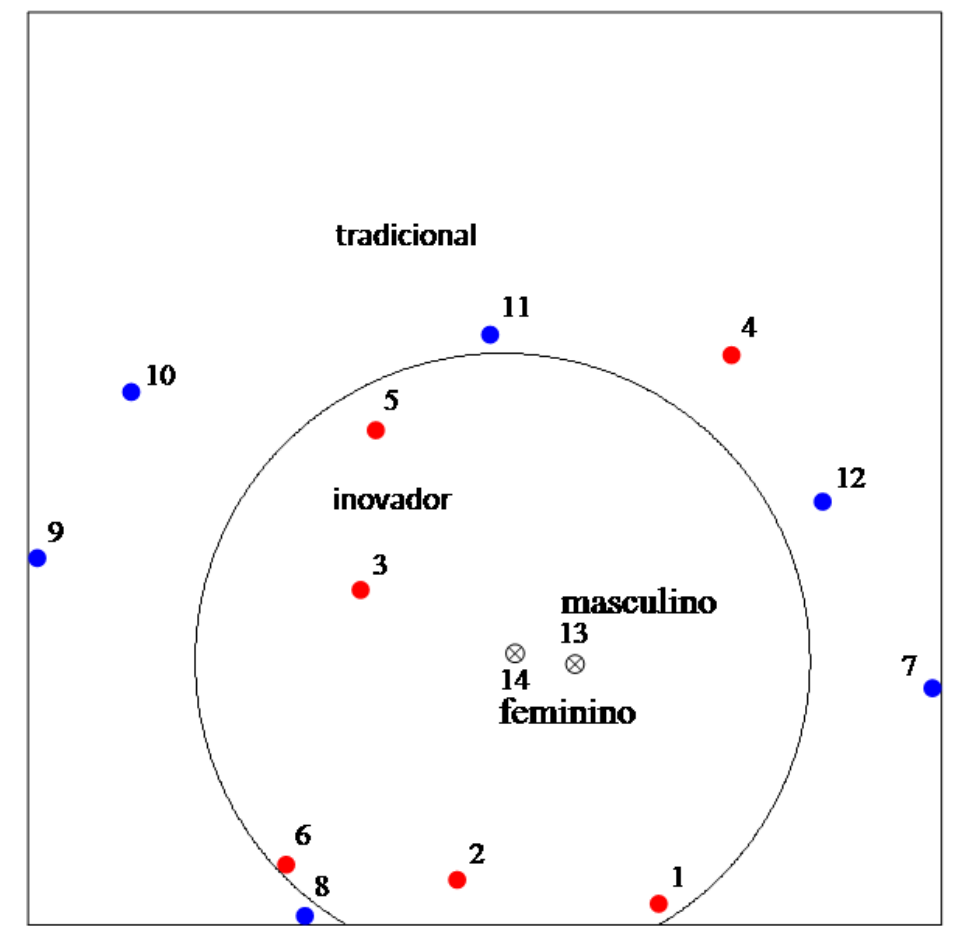

Figura 8: Diagrama do espaço da SSA com o teste para a FACETA Y (NOVIDADE)

O padrão modular revela que essa faceta é relevante na avaliação realizada, qualidade visual percebida em cenas de salas de estar, pois está relacionada com uma ou mais facetas da sentença estruturadora. Pode-se ainda afirmar, que o caráter inovador das cenas influencia mais os idosos participantes, de ambos os sexos, do que o caráter tradicional.

Ainda observando o mapa do SSA para essa faceta nota-se apenas uma única exceção, representada pela cena 4, que foi inicialmente definida como inovadora, mas percebida como tradicional pelos participantes. Essa exceção, contudo, não inviabiliza os resultados para a faceta.

No mapa do SSA da Faceta Y (Figura 8) observa-se que ambos os grupos, masculino e feminino, estão localizados na mesma região do diagrama, que reúne cenas de salas de estar inovadoras. Isso revela que há consenso desses resultados entre os grupos de participantes idosos do sexo masculino e feminino.

Ao analisar o mapa da SSA para a Faceta Z, abertura, também se notou que os participantes captaram tanto a categoria como seus dois diferentes níveis, obstruída e desobstruída, uma vez que, foram formadas regiões de similaridades coerentes com a ordem hierárquica considerada para o seu conteúdo (elementos internos). 
A Figura 9, de modo semelhante às demais, mostra uma forma circular, que divide o mapa em duas regiões distintas, uma mais central, que reúne as cenas de salas de estar com vistas desobstruídas, e outra mais periférica, que reúne as cenas com um caráter oposto. De forma inequívoca, essa faceta desempenha um papel modular, muito relevante para o tipo de avaliação realizada, já que tem relação com uma ou mais facetas da sentença estruturadora.

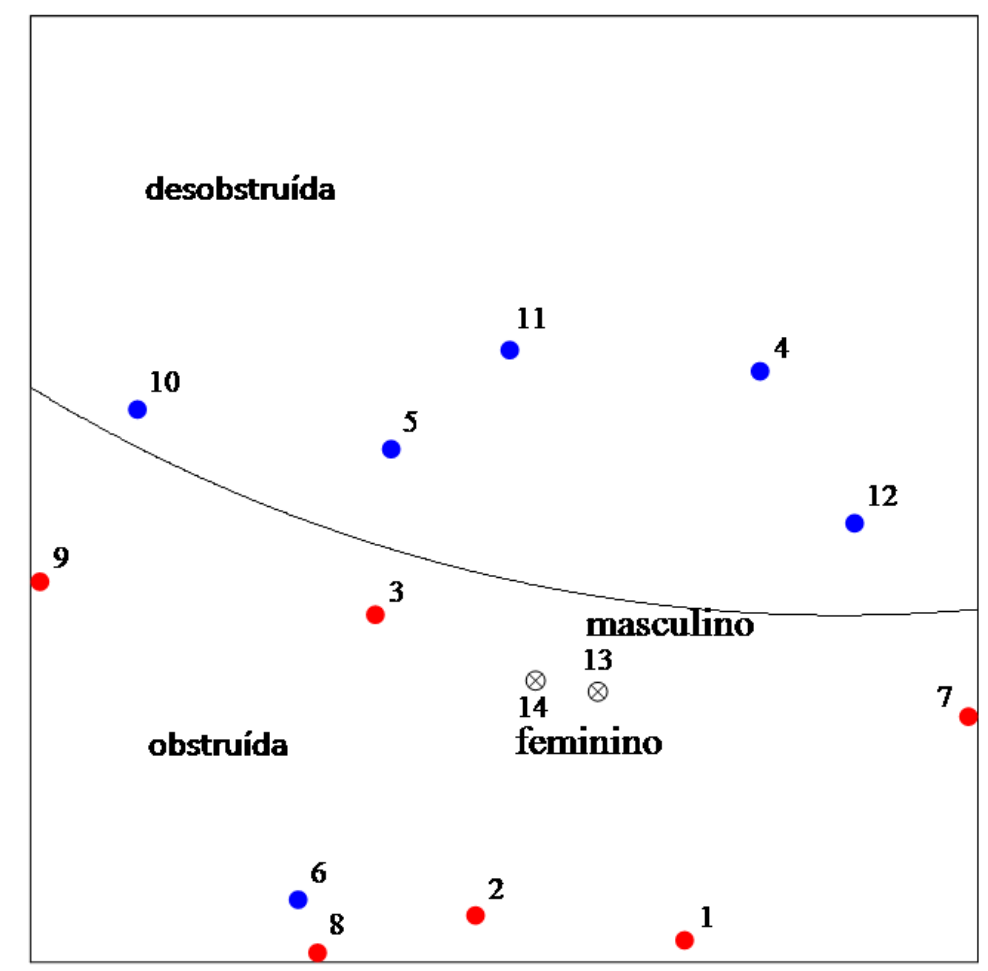

Figura 9: Diagrama do espaço da SSA com o teste para a FACETA Z (ABERTURA)

A visão desobstruída, portanto, pela sua localização na forma modularmente central da partição do mapa da SSA, indica que os idosos participantes são mais influenciados no tipo de avaliação realizada pelas cenas de salas de estar desobstruídas.

Explorando um pouco mais o mapa da Faceta Z (Figura 9), nota-se apenas uma exceção, a cena de número 6, inicialmente escolhida como desobstruída, mas percebida como obstruída.

Ainda em relação ao mapa da Faceta Z (Figura 9), nota-se que tanto o grupo de idosos masculino quanto o feminino está localizado na mesma região do mapa da SSA, que agrupa cenas de salas de estar com vista obstruída. Há, portanto, consenso desses resultados entre os grupos de participantes idosos do sexo masculino e feminino.

Considerando os escores atribuídos pelos idosos participantes para cada uma das fotos (Figura 10), a cena $X 3 Y 2 Z 2$, representando uma sala de estar típica, com complexidade máxima e vista desobstruída, foi avaliada como a menos preferida; enquanto a cena X2Y2Z1, retratando uma sala de estar típica, com complexidade moderada e vista desobstruída, foi escolhida como a cena mais preferida. Já a Figura 11 e a Figura 12 mostram, respectivamente, a cena menos preferida e a mais preferida pelos idosos abordados, ou seja, aquelas com maior e menor qualidade visual percebida. 


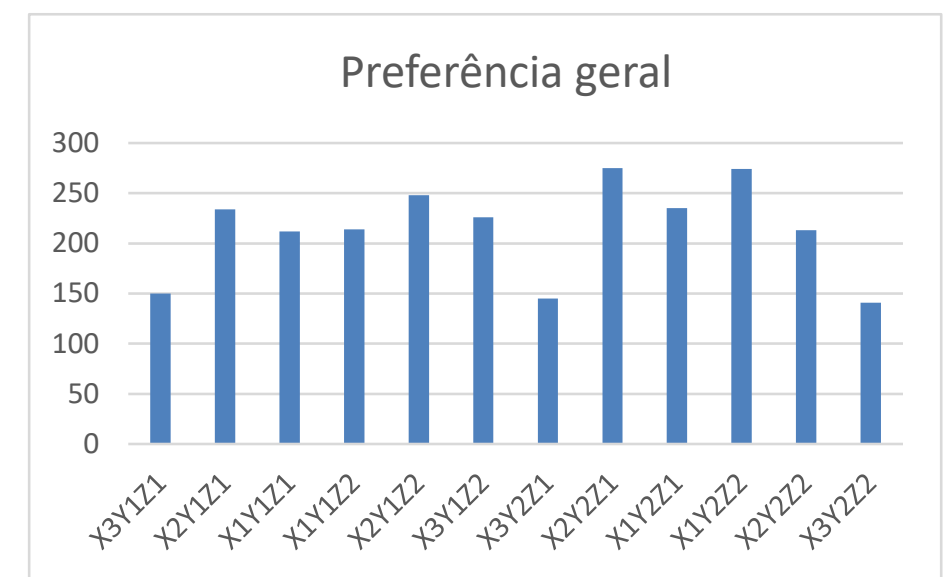

Figura 10: Escores obtidos nas doze cenas de salas de estar utilizadas na pesquisa.

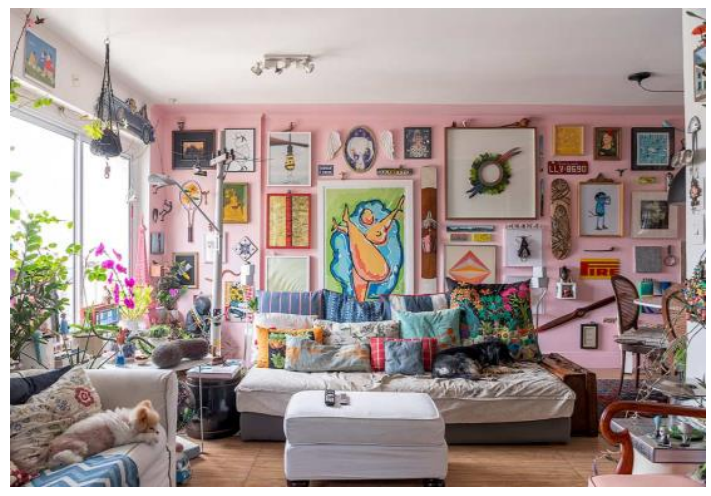

Figura 11: Cena MENOS preferida

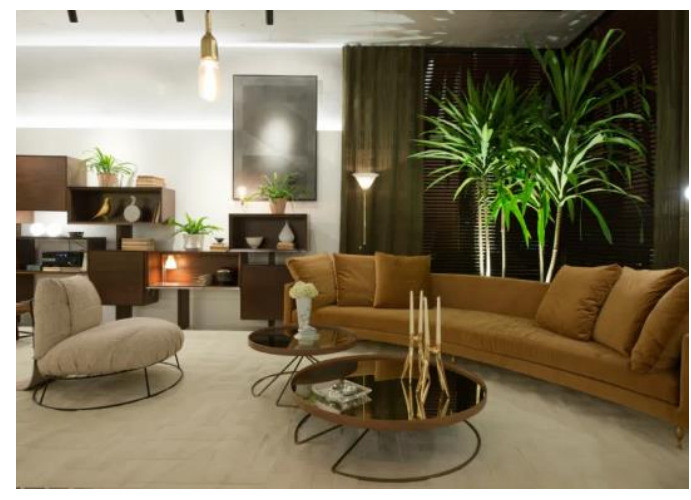

Figura 12: Cena MAIS preferida

Com base nesses últimos resultados destacados, apurou-se que a característica ambiental de complexidade - diferente da novidade e da abertura -, sofreu alteração para as cenas de salas de estar mais preferida e menos preferida. Isso indica que a complexidade da cena parece ter um efeito mais decisivo na preferência visual por cenas de salas de estar, segundo a percepção dos idosos respondentes.

\section{Conclusão}

Não obstante as variáveis testadas abrangerem apenas três características dos elementos ambientais, os resultados obtidos podem enriquecer questões, soluções e abordagens consideradas por pesquisadores, projetistas, educadores e outros sobre a qualidade visual percebida em cenas de salas de estar para idosos.

O método multidimensional e não paramétrico usado para análise dos dados - Análise da Estrutura de Similaridade - foi satisfatório para a avaliação realizada, além de ter possibilitado prover informações empíricas que não seriam possíveis através de uma análise convencional.

Nesta pesquisa, a sentença estruturadora para a avaliação da qualidade visual percebida em cenas de salas de estar foi corroborada, visto que, tanto as facetas relacionadas como variáveis de conteúdo quanto os seus elementos internos foram captados pelos idosos participantes. 
Foi apurado que as características de complexidade, novidade e abertura são aderentes para a avaliação da qualidade visual percebida por idosos em cenas de salas de estar.

Sobre os efeitos da complexidade, da novidade e da abertura para a qualidade visual percebida em cenas de salas de estar, verificou-se que os idosos participantes da pesquisa são influenciados por aquelas de caráter inovador, com complexidade moderada e vistas desobstruídas, sendo esses três diferentes níveis/aspectos centrais para esse tipo de avaliação.

Apurou-se, ainda, que houve consenso dos resultados obtidos entre os dois diferentes grupos de idosos do sexo feminino e masculino participantes desta pesquisa.

Considera-se, portanto, que o objetivo geral da pesquisa - prover informações empíricas sobre os efeitos da complexidade, da novidade e da abertura em cenas de salas de estar na qualidade visual percebida por idosos - foi plenamente atendido.

Espera-se que as informações empíricas, apuradas nesta pesquisa possam ser tomadas como diretrizes projetuais no sentido de favorecer a qualidade visual percebida em salas de estar para idosos e, por conseguinte, a qualidade de vida dessa população em constante crescimento.

\section{Referências}

AMAR, Reuven; LEVY, Shlomit. SSA: Similarity Structure Analysis. In: MICHALOS, Alex. Encyclopedia of Quality of Life and Well-Being Research. Springer, Dordrecht. 2014.

BERLYNE, Daniel. Ends and meanings of experimental aesthetics. Canadian Journal of Psychology, online, v. 26, n. 4, p. 303-325, 1972.

BILSKY, Wolfgang. A Teoria das Facetas: noções básicas. Estudos de Psicologia, v.8, n.3, p. 357-365, 2003.

BONAIUTO, Marino; FORNARA, Ferdinando; BONNES, Mirilia. Indexes of perceived residential environment quality and neighbourhood attachment in urban environments: a confirmation study on the city of Rome. Landscape and Urban Planning, online, v. 65, n. $1-2$, p. 41-52. 15 set. 2003.

BORG, Ingwer; LINGOES, James. SSA as Multidimensional Scaling. In: BORG, Ingwer; LINGOES, James. Multidimensional Similarity Structure Analysis. Springer, New York, NY. 1987, p. 236-24.

CANTER, David; BROWN, Jennifer; GROAT, Linda. Multiple Sorting Procedure for study conceptual systems. In CANTER, David; BROWN, Jennifer; BRENNER, Michael. Research Interview: use and approaches. London: John Wiley, 1985, p. 79-114.

COSTA FILHO, Lourival. MIDIÁPOLIS: comunicação, persuasão e sedução da paisagem urbana midiática. 2012. 271 p. Tese (Doutorado). UFPE, Recife, 2012.

O enfoque da teoria das facetas na avaliação de lugares. V Encontro Nacional de Ergonomia do Ambiente Construído \& VI Seminário Nacional de Acessibilidade Integral, 2014, Rio de Janeiro. Anais...Rio de Janeiro: PUC-Rio, 2014.

GROAT, Linda. Meaning in post-modern architecture: An examination using the multiple sorting task. Journal of Environmental Psychology, online, v. 2, n. 1, p. 3-22, 1982.

HEATH, Tom. Behavioral and perceptual aspects of the aesthetics of urban environments. In NASAR, Jack. Environmental aesthetics: theory, research, and application. New York: Cambridge University Press, 1988. Cap. 1, p. 6-10. 
IBGE. Pirâmide etária. S./d. https://educa.ibge.gov.br/jovens/conheca-obrasil/populacao/18318-piramide-etaria.html

KAPLAN, Stephen. Perception and landscape: conceptions and misconceptions. In NASAR, Jack. Environmental aesthetics: theory, research, and application. New York: Cambridge University Press, 1988. Cap. 4, p. 45-55.

KUNST, Marina; BRANDÃO, José; PAIVA, Marie.; VILLAROUCO, Vilma. Análise das dimensões dos espaços de um conjunto habitacional para idosos. Revista Projetar: Projeto e Percepção do Ambiente, online, v. 6, n. 1, p. 85-99, 25 jan. 2021.

LEWIS, Camilla; BUFFEL, Tine. Aging in place and the places of aging: A longitudinal study. Journal of Aging Studies, online, v. 54, set. 2020.

MORAIS, Kátia. Travessias do tempo: elegendo caminhos sem obstáculos para um envelhecimento ativo na Unati/UFPE. 2016. 211 p. Dissertação (Mestrado) - Universidade Federal de Pernambuco, Recife, 2016.

NASAR, Jack. The evaluative image of places. In NASAR, Jack. Environmental aesthetics: theory, research, and application. New York: Cambridge University Press, 1988. p. 117-168.

Visual Quality by Design. Holland MI: American Society of Interior Designers, Haworth Inc., 2008.

The effect of sign complexity and coherence on the perceived quality of retail scenes. In NASAR, J. L. (Ed.). Environmental Aesthetics: theory, research, \& applications. New York: Cambridge University Press, 1988. p. 300-320.

OLIVEIRA, Anderson; ROSSI, Elaine. Envelhecimento populacional, segmento mais idoso e as atividades básicas da vida diária como indicador de velhice autônoma e ativa. Revista GEOSUL, online, v. 34, n. 73, p. 358-377, 06 dez. 2019. Periodicidade quadrimestral.

OSWALD, Frank; WAHL, Hans-Werner. Dimensions of the meaning of home. In: ROWLES, Graham; CHAUDHURY, Habib. Home and Identity in Late Life: International Perspectives, Springer Publishing Company, 2005. Cap. 2, p. 21-45.

PORTO, Camila; REZENDE, Edson. Terceira idade, design universal e aging-in-place. Estudos em Design, Revista (online), Rio de Janeiro, v. 24, n. 1, p. 152 - 168, 2016.

ROAZZI, Antonio; DIAS, Maria. Teoria das facetas e avaliação na pesquisa social transcultural: Explorações no estudo do juízo moral. In: Conselho Regional de Psicologia 13a Região $\mathrm{PB} / \mathrm{RN}$. A diversidade da avaliação psicológica: Considerações teóricas e práticas. João Pessoa: Ideia, 2001, p. 157-190.

ROWLES, Graham; OSWALD, Frank; HUNTER, Elizabeth. Interior Living Environments. In Old Age: Annual Review of Gerontology and Geriatrics, v. 23, p. 167 - 194, jan. 2003.

SILVA, Renan; COSTA FILHO, Lourival. Coerência, complexidade e novidade percebidas em dispositivos de pulso para corredores. Ergodesign \& HCI, v. 8, p. 116-130, 2020.

\section{Sobre os autores}

\section{Marina Holanda Kunst}

Graduada em Economia Doméstica, pela Universidade Federal Rural de Pernambuco, Especialista em Neurociências Multiprofissional, Mestre em Desenvolvimento Urbano e Doutoranda em Design, os dois últimos pela Universidade Federal de Pernambuco. Participa do grupo de pesquisa em Ergonomia Aplicada ao Ambiente Construído (CNPq), desenvolvendo trabalhos voltados à qualidade de vida e melhoria dos espaços vivenciados pelos e para os idosos. ORCID https://orcid.org/0000-0002-5577-0286 


\section{Lourival Costa Filho}

Tem Graduação em Arquitetura e Urbanismo, Especialização em Ergonomia e em Neurociências Multiprofissional, Mestrado em Design e Doutorado em Desenvolvimento Urbano. É Professor do Curso de Design, da Pós-Graduação em Design e da Pós-Graduação em Ergonomia, todos na Universidade Federal de Pernambuco. É Vice-Líder do Grupo de Pesquisa Ergonomia Aplicada ao Ambiente Construído (CNPq) e pesquisador do Labergo/design (CNPq).

ORCID https://orcid.org/0000-0001-7700-7735 